DIW BERLIN

Discussion

Papers

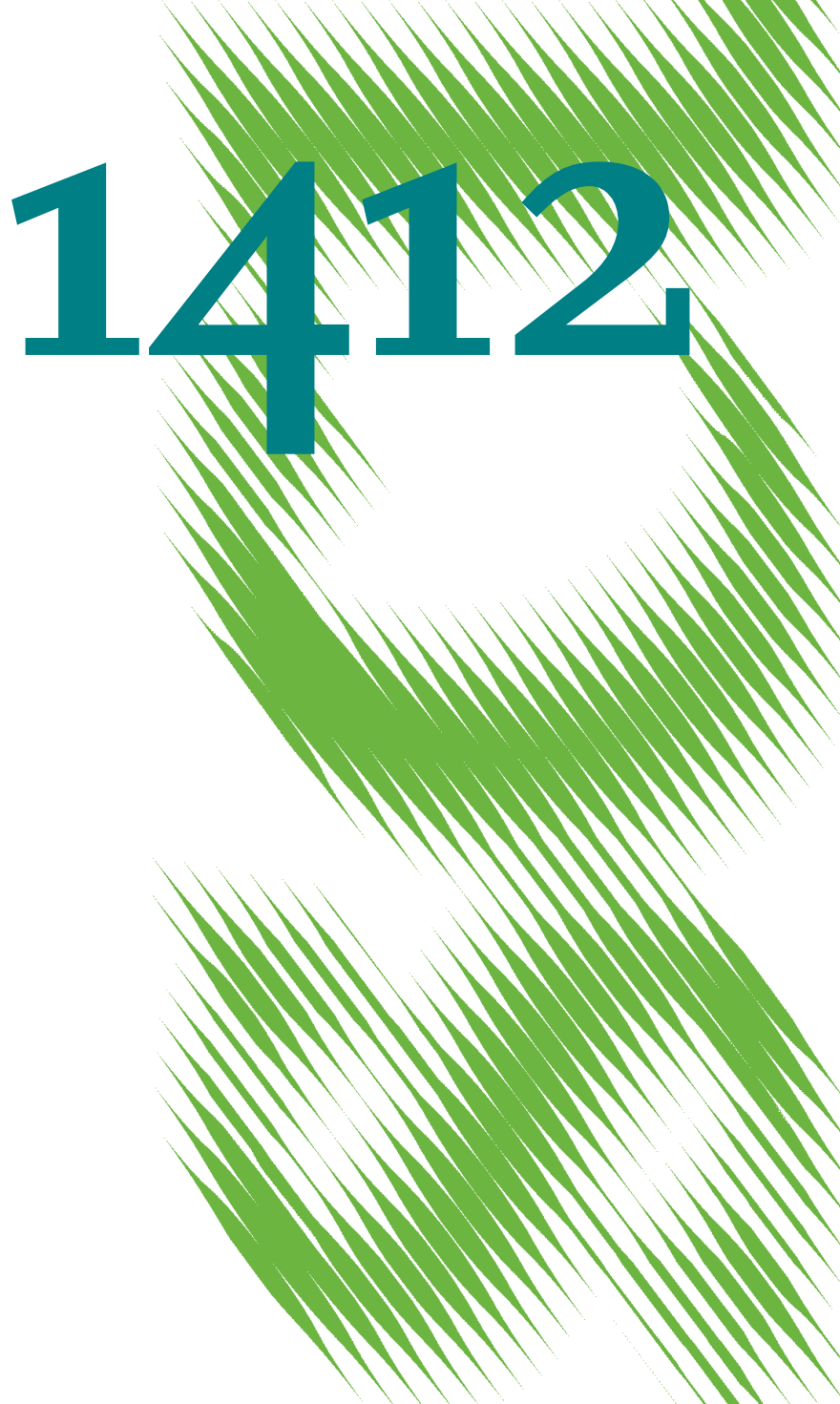

Log versus Level in VAR Forecasting: 42 Million Empirical Answers Expect the Unexpected 
Opinions expressed in this paper are those of the author(s) and do not necessarily reflect views of the institute.

IMPRESSUM

(C) DIW Berlin, 2014

DIW Berlin

German Institute for Economic Research

Mohrenstr. 58

10117 Berlin

Tel. +49 (30) $89789-0$

Fax +49 (30) $89789-200$

http://www.diw.de

ISSN electronic edition 1619-4535

Papers can be downloaded free of charge from the DIW Berlin website:

http://www.diw.de/discussionpapers

Discussion Papers of DIW Berlin are indexed in RePEc and SSRN:

http://ideas.repec.org/s/diw/diwwpp.html

http://www.ssrn.com/link/DIW-Berlin-German-Inst-Econ-Res.html 


\title{
Log versus level in VAR forecasting: 42 Million empirical answers \\ - expect the unexpected
}

\author{
Johannes Mayr* and Dirk Ulbricht ${ }^{\dagger}$
}

October 14, 2014

\begin{abstract}
The use of log-transformed data has become standard in macroeconomic forecasting with VAR models. However, its appropriateness in the context of out-of-sample forecasts has not yet been exposed to a thorough empirical investigation. With the aim of filling this void, a broad sample of VAR models is employed in a multi-country set up and approximately 42 million pseudo-out-of-sample forecasts of GDP are evaluated. The results show that, on average, the knee-jerk transformation of the data is at best harmless.
\end{abstract}

JEL classifications: C52, C53

Keywords: VAR-forecasting, logarithmic transformation

*Bayerische Landesbank.

†DIW, Berlin, dulbricht@diw.de, Mohrenstr. 58, 10117 Berlin 


\section{List of Tables}

$1 \quad$ Descriptive Statistics, United States . . . . . . . . . . . . . . . . . . . . . . . . . . . . . . 10

2 Descriptive Statistics, Japan . . . . . . . . . . . . . . . . . . . . . . . . . . . . . . . . . . . 11

3 $\quad$ Descriptive Statistics, United Kingdom . . . . . . . . . . . . . . . . . . . . . . . . . . . . . . . 11

4 Descriptive Statistics, Germany . . . . . . . . . . . . . . . . . . . . . . . . . . . . . 12

$5 \quad$ Sample size and number of iterations by country . . . . . . . . . . . . . . . . . . . . . . . . . 12

$6 \quad$ Comparison of level forecasts and forecasts of naïve and unbiased log-transformed models, USA 13

7 Comparison of level forecasts and forecasts of naïve and unbiased log-transformed models, Japan . . . . . . . . . . . . . . . . . . . . . . . . . . . . . . . 13

8 Comparison of level forecasts and forecasts of naïve and unbiased log-transformed models, Germany ................................... . . 14

$9 \quad$ Comparison of level forecasts and forecasts of naïve and unbiased log-transformed models, UK 14

\section{Introduction}

In the field of forecasting macroeconomic time series with vector autorregressive (VAR) models, the use of log-transformed data has become standard or at least good practice. Variables are transformed in order to obtain a more homogenous variance or so that the resulting series become more similar to a normal distribution. Though very easily implemented, taking logarithms is just one out of a wide range of possible transformations that can be represented in the setting provided by Box-Cox. Thus, a forecaster has to decide, a priori, if to transform the original series and which of the many transformations is best. Unfortunately, most of these issues concerning data transformations for forecasting purposes are only addressed in the univariate context and are of limited use. This paper helps to fill this void focusing on the importance of transformation, shedding light on the chances that taking logs leads to an improvement and on the risks that this leads to a deterioration of forecast accuracy.

To choose between the use of data in levels $\mathrm{s}^{1}$ and transformed data, several in-sample statistical tests based on the Box-Cox-transformation have been developed and applied (see for example Shin and Kang

\footnotetext{
${ }^{1}$ Note that data in levels in this context means non-logarithmic data.
} 
2001). However, macroeconomic forecasters are typically interested in the out-of-sample forecast accuracy of a model. Proietti and Lütkepohl 2013 present a distribution free, nonparametric method for estimating the Box-Cox transformation parameter for autoregressive integrated moving average (ARIMA) models. They perform a large scale out-of-sample forecast comparison based on 530 monthly, seasonal time series related to industrial production and retail turnover of a large number of countries. They show that in about threequarters of the series analyzed, their method provides a reliable ex-ante guidance. Unfortunately, they do not report the percentage of times, the method leads to a statistically significant deterioration.

Proietti and Lütkepohl [2013] also give an indication how to transform the data, and quantify potential gains of transformation. They demonstrate that in most cases simply taking logs is the best choice if a transformation is needed. In at least 20 percent of their series, forecast accuracy can significantly be improved using transformed data when one-step-ahead horizons are considered. For longer horizons, the improvements are markedly smaller. However, Proietti and Lütkepohl 2013 do not indicate how often taking logarithms or any of the transformations they report leads to a deterioration of the forecasts. Lütkepohl and Xu 2012 conduct pseudo-out-of sample experiments predicting stock indices, and GDP and consumption of mayor economies employing univariate models. They find that taking logarithms improves forecasts if the log transformation makes the variance more homogeneous throughout the sample. However, taking logs can lead to forecast deterioration if this does not stabilize variances. Lütkepohl and $\mathrm{Xu}$ [2011] consider univariate predictions of annual inflation rates for a number of European countries and the USA using monthly seasonal consumer price indices. Models based on logs are outperformed by models in levels most of the time. If log-models are more accurate, the gains are very small.

When it comes to VAR forecasting, the secondary, but nonetheless important, issue of how to re-transform forecasts back to levels is intensely discussed in the literature. Theoretically, taking the exponent of forecasts made in logs (naïve approach) is a biased predictor for the data in levels. Building on the findings of Granger and Newbold 1976, Ariño and Franses 2000 derive optimal forecasts and demonstrate their superiority in an forecast experiment involving a bi-variate VAR of US gross national product and real gross domestic investment. As a byproduct, they demonstrate that biased and unbiased log-transformed forecasts outperform level forecasts. However, Bårdsen and Lütkepohl 2011] show, in a simulation study and an empirical experiment based on the up-dated data set used by Ariño and Franses [2000], that theoretically optimal 
predictors are inferior to forecasts based on the exponential transformation if estimation and specification uncertainty is properly taken into account.

Given the scarce evidence of success or failure of log transformations of data in VAR forecasting, we try to shed some light on the issue focusing on the central variable for economic forecasting, the GDP. A broad sample of models is employed over different estimation periods and forecast horizons. It is thereby assumed that the researcher is interested in the forecasts of the levels of a time series. In order to re-transform the forecasts of the estimations in log-transformed data back to levels the adjusted re-transformation approach following the lines of Ariño and Franses [2000] as well as the "naïve" approach, i.e. simply using the exponential of the logarithmic forecast values, are considered and evaluated. In order to put the results of our study on a firm empirical footing, the analysis is implemented on a $\mathrm{G} 4^{2}$ data set. All reasonable combinations of the variable of interest, the real GDP, and an extended set of additional macroeconomic variables are estimated employing VAR models. Using a recursive window approach, for each model the 1 to 8 step ahead pseudo out-of-sample forecasts based on an estimation in log-transformed data and on levels of the time series are compared. The results show that according to the forecast performance the standard use of log-transformed data at least has to be questioned. This finding is independent of the use of the optimal or the "naïve" re-transformation approach. Our paper is structured as follows. Section 2 presents the data, Section 3 outlines the procedure of the analysis, Section 4 presents the results, and Section 5 concludes.

\section{The data}

The data entering the VAR-models are standard macroeconomic time-series most commonly used for forecasting purposes. They have been obtained from the International Monetary Fund (IMF), Eurostat and/or national statistic agencies. Additionally to the standard macroeconomic VAR setup linking GDP, the policy interest rate and a measure for the consumer prices, several other aggregates and indicators that correlate with real GDP are included. The real effective exchange rate, the imports and exports series as well as the commodity prices cover the external influences. The major stock-price indices, the unemployment rate, industrial production, consumption, investment, hours worked and several early indicators such as industrial

\footnotetext{
${ }^{2}$ The G4-countries comprise Germany, Great Britain, Japan, and the United States of America
} 
orders, consumer and producer sentiments complete the set. The data, especially in the case of the early indicators, differ between the countries. A complete list of the variables included, as well as some basic descriptive statistics for the USA, Japan, Germany, and the UK are given in Tables 1, 2, 3 and 4 respectively. The sample sizes are given in Table 5 . The number of observations ranges from 93 quarters in the case of Germany to 177 in the case of the United States (see Table 2). The relatively small number of observations for Germany is due to the structural break stemming from German reunification in 1990. Given the variable of interest being GDP, the analysis is restricted to quarterly data.

\section{Procedure of the Analysis}

The models are formed using all possible combinations of the regressors including $k=1, \ldots, 5$ additional variables and GDP. The maximum of $k$ is set to 5 in view of the limited number of observations in the time dimension. Given that the total number of exogenous regressors is $N=16$, the number of models formed is $M=6884$. These models are recursively estimated in a pseudo-out-of-sample forecast experiment:

1. We employ an expanding window approach making use of all the data up to the forecast origin. In the first recursion, the minimum number of observations is $t_{\text {min }}=40$.

2. The VAR models of the form:

$$
D\left(y_{i}(t)\right)=B_{0}+\sum_{r=1}^{p} B_{r} D\left(y_{i}(t-r)\right)+\epsilon(t),
$$

are estimated for level data, $i=l e v e l$, and log-transformed data, $i=l o g$. In order to address nonstationarity, the estimations are performed in first differences. $D()$ is the difference operator, $D\left(y_{i}(t)\right)=$ $\left(D\left(y_{1}(t)\right), \ldots, D\left(y_{k}(t)\right)\right)$ is a $k$-dimensional VAR process of order $p$ and $\epsilon(t) \sim N\left(0, \Sigma_{\epsilon}\right)$ is Gaussian white noise.

3. The lag-length $p$ is selected using the Akaike information criterion.

4. 1 to 8 quarters level forecasts are made

(a) based on the estimated models in levels, $i=$ level (level forecast) 
(b) based on the estimated models employing log-transformed data, $i=\log$ taking exponents of the forecasts (naïve logarithmic forecast)

(c) based on the estimated models employing log-transformed data, $i=\log$, taking exponents and adjusting for the forecast error variance (optimal forecast) as proposed by Ariño and Franses $20003^{3}$

5. The differencing is undone.

6. In the next recursion, one more observation is added ${ }^{4}$

For the last recursion the number of observations is $t_{\max }=T-8$, where $T$ is the total number of observations. The number of recursions is $N_{r e c}=t_{\max }-t_{\min }+1$. The full sample, the first iteration, and the number of recursions for each country is given in Table 5 in the Appendix.

After all recursions are run the level, naïve, and optimal forecast errors are compared using the HNLstatistic proposed by Harvey et al. 1997. 5

\footnotetext{
${ }^{3}$ In order to highlight the difference between a biased and an unbiased forecast when taking logarithms are concerned, we consider the case of forecasting a univariate time series $x_{t}$ following Granger and Newbold 1976. The series $y_{t}$ corresponds to the natural logarithmic transformation of $x_{t}$, so that $y_{t}=\log \left(x_{t}\right)$. The log-transformed time series $y_{t}$ can be written as $y_{t}=m_{t}+\epsilon_{t}$ with $m_{t}$ being the conditional expectation of $y_{t}$, given the information set at time $t$, and with $\epsilon_{t}$ being a standard white noise process. The exponential of the forecast of $y_{t+k}$ is referred to as the "naïve" forecast of $x_{t+k}$ :
}

$$
\hat{x}_{t+k}^{*}=\exp \left(\hat{m}_{t+k}\right)
$$

As shown by Granger and Newbold 1976, this "naïve" forecast does not equal the expected value of the time series $x_{t+k}$ in levels at time $t$. It is biased since the expected value of the exponential of the forecast error $\eta_{t+k}$ unequals one. The unbiased forecast $\hat{x}_{t+k}$ of the variable $x_{t+k}$ in levels can be written as:

$$
\hat{x}_{t+k}=E_{t}\left[\exp \left(m_{t+k}+\eta_{t+k}\right)\right]=\hat{x}_{t+k}^{*} E_{t}\left[\exp \left(\eta_{t+k}\right)\right]
$$

where $E_{t}$ is the expectation operator at timet. Granger and Newbold 1976 showed that the required correction factor $E_{t}\left[\exp \left(\eta_{t+k}\right)\right]$ equals $\exp \left(\sigma_{k}^{2} / 2\right)$ where $\sigma_{k}^{2}$ is the variance of the $k$-step ahead forecast error of variable $y$.

${ }^{4}$ In total this gives about 42 million forecasts (number of forecasts for each country=number of models $\times$ number of iterations $\times$ number of horizons $\times$ of transformations)

${ }^{5}$ To test whether or not two forecasts generated by different models are significantly different in one direction, i.e. whether one of them is significantly superior to the other several procedures have been developed. Diebold and Mariano 2002 proposed a test (DM test) of the null hypothesis of no difference in the accuracy of two competing forecasts that is widely applicable. Their test allows for a wide class of measures of forecast accuracy and is not restricted to a single loss function. The test considers the null hypothesis $H_{0}: E\left[\delta_{t}\right]=0$. and is based on the observed sample mean

$$
\bar{d}=\frac{1}{T^{*}} \sum_{t=T_{0}}^{T} d_{t}
$$

with $T=T-T_{0}+1$. The sequence of the forecast errors follows a moving average process of order $q=(k-1)$. If the autocorrelations of order $k$ and higher are zero, the variance of the loss differential can be heteroscedastic and autocorrelation 


\section{Results}

Tables 6, 7, 8 , and 9 present the results for the USA, Japan, Germany, and the United Kingdom respectively. They compare the performance of level to naïve forecasts (column 1 and 2), level to optimal forecasts (column 3 and 4), and naïve to optimal forecasts (column 5 and 6 ). The percentages presented show how many times one type had a smaller forecast error, that is, outperforming the alternative, and how many times the respective forecast was outperformed. An outperformance is indicated by the HNL-test.

Log-transforming data or not makes a difference, though the effect is mostly small when looking at the percent of times one type of transformation dominates the other and it is not completely one-directional. With the aim of concentrating on the more important results, in the following, we ignore numbers below 5 percent. For all countries the results for optimally retransformed data and naïve log-transformed are virtually identical. For US data, level forecasts outperform log-transformed forecasts at a forecast horizon of one and two quarters at 5.6 and 6 percent of the times, respectively. Still, for one and two quarter horizons, logtransformed forecasts outperform their level counterparts at 12.8 and 6.5 percent of times. For Japan, level data outperform log-transformed data for longer forecast horizons above or about 8 percent for 3 to 8 month horizons, having a maximum of 10.7 percent for the one-year horizon. For one and two quarter horizons, log-transformed data dominate in 13.7 and 6.5 percent of times, while they are outperformed only in 5.3 percent of times by forecasts based on level data. In contrast, in the case of Germany, level data dominate for the one quarter horizon giving a value of 5.4. All other percentages are below 3 for all horizons and consistently (HAC) estimated as

$$
\bar{V}=\frac{1}{T^{*}}\left(\hat{\gamma}_{0}+2 \sum_{j=1}^{k-1} \hat{\gamma_{j}}\right)
$$

where $\hat{\gamma}_{j}$ is the estimated $j-$ th autocovariance of the loss differential $t$. Under the null hypothesis of equal forecast accuracy the DM test statistic can be computed as:

$$
D M=\frac{\bar{d}}{\sqrt{V}} \sim N(0,1)
$$

To test if a model $i$ is not dominated by a model $j$ in terms of forecast accuracy, a one-sided DM test has to be conducted. The modified null hypothesis is than given by $H_{0}=E\left[\delta_{t}\right]$. If the null is rejected one thus concludes that model $j$ dominates model $i$. In order to reduce size distortions that might be significant in small samples Harvey et al. 1997. suggest a corrected DM statistic:

$$
H L N=D M\left(\frac{T^{*}+1-2 k+k(k-1) / T^{*}}{T^{*}}\right)^{0.5}
$$

The modified statistic is compared to a Student's t-distribution with $\mathrm{T}-1$ degrees of freedom. 
directions of comparison. For the UK level data outperform log-transformed data for one quarter horizons in 21 percent of the comparisons and is outperformed by log-transformed only 5.8 percent of times. For the two quarter horizon level data still outperform log-transformed data in 8.5 percent of times.

\section{Conclusion}

VAR models are an essential tool for practitioners when it comes to forecasting macroeconomic time series. Log-transforming the data is common practice. The rationale behind this is that the log-transformation helps to overcome the detrimental effects of heteroscedasticity and skewness in the level data on estimation and testing. Our goal is to empirically evaluate the appropriateness of this approach in the context of forecasting with VAR models. In a recursive scheme, VAR models using data of the G4 countries are estimated in logarithms as well as in levels and used to forecast 1 to 8 quarters ahead. The resulting logarithmic forecasts are transformed to levels and the forecast errors are compared to the ones of the respective level models. The re-transformation of the logarithmic forecasts to levels simply taking the exponential leads to biased forecasts. Therefore, additionally, the optimal re-transformation proposed by Ariño and Franses [2000] is applied, as well. However, the two approaches basically yield the same results. One-sided HNL tests show, differences are more relevant at shorter forecast horizons. For one quarter horizon forecasts, models based on level data are more successfull than the ones based on log-transformed data for the USA and Japan. For Germany and the UK, it is the other way round.

Potential gains and risks of selecting the right transformation reach relevant levels only in one case. The maximum of percentage outperformance is given for one quarter forecasts of UK GDP level forecasts dominating log-transformed forecast in 21 percent of the cases ${ }^{6}$ Overall, our analysis based on broad empirical evidence demonstrates that the automatic transformation of the data is at best harmless.

\footnotetext{
${ }^{6}$ The second highest outperformance is 13.65 percent in the case of one quarter horizon forecasts for Japan. Here logtransformed data outperform level data.
} 


\section{References}

Miguel A Ariño and Philip Hans Franses. Forecasting the levels of vector autoregressive log-transformed time series. International Journal of Forecasting, 16(1):111-116, 2000.

Gunnar Bårdsen and Helmut Lütkepohl. Forecasting levels of log variables in vector autoregressions. International Journal of Forecasting, 27(4):1108-1115, 2011.

Francis X Diebold and Robert S Mariano. Comparing predictive accuracy. Journal of Business $E$ G economic statistics, 20(1), 2002.

Clive WJ Granger and Paul Newbold. Forecasting transformed series. Journal of the Royal Statistical Society. Series B (Methodological), pages 189-203, 1976.

David Harvey, Stephen Leybourne, and Paul Newbold. Testing the equality of prediction mean squared errors. International Journal of forecasting, 13(2):281-291, 1997.

Helmut Lütkepohl and Fang Xu. Forecasting annual inflation with seasonal monthly data: Using levels versus logs of the underlying price index. Journal of Time Series Econometrics, 3(1), 2011.

Helmut Lütkepohl and Fang Xu. The role of the log transformation in forecasting economic variables. Empirical Economics, 42(3):619-638, 2012.

Tommaso Proietti and Helmut Lütkepohl. Does the box-cox transformation help in forecasting macroeconomic time series? International Journal of Forecasting, 29(1):88-99, 2013.

Key-Il Shin and Hee-Jeong Kang. A study on the effect of power transformation in the arma (p, q) model. Journal of Applied Statistics, 28(8):1019-1028, 2001. 


\section{Appendix}

Table 1: Descriptive Statistics, United States

\begin{tabular}{|c|c|c|c|c|c|c|c|}
\hline Variable & mean & median & $\begin{array}{l}\text { standard } \\
\text { deviation }\end{array}$ & minimum & maximum & $\begin{array}{c}\text { seasonal } \\
\text { adjustment }\end{array}$ & $\begin{array}{c}\text { constant } \\
\text { prices }\end{array}$ \\
\hline Business confidence & 54.65 & 55.10 & 9.00 & 25.70 & 77.10 & $\mathrm{x}$ & \\
\hline Exports & 1378.75 & 1103.14 & 1105.24 & 97.45 & 4037.54 & $\mathrm{x}$ & $\mathrm{x}$ \\
\hline Government bond rates, long-term & 7.14 & 6.86 & 2.61 & 2.37 & 14.50 & & \\
\hline Government spending & 2193.58 & 2242.10 & 552.47 & 1406.40 & 3113.00 & $\mathrm{x}$ & $\mathrm{x}$ \\
\hline Gross domestic product & 9823.75 & 9113.20 & 3562.88 & 4702.80 & 15942.30 & $\mathrm{x}$ & $\mathrm{x}$ \\
\hline Hourly earnings & 34.70 & 34.40 & 1.03 & 33.10 & 37.30 & $\mathrm{x}$ & \\
\hline Hours worked & 11.15 & 10.67 & 4.99 & 3.33 & 20.45 & $\mathrm{x}$ & \\
\hline Imports & 2043.84 & 1269.28 & 1775.34 & 97.21 & 5747.38 & $\mathrm{x}$ & $\mathrm{x}$ \\
\hline Industrial production & 68.72 & 62.72 & 20.64 & 36.69 & 102.23 & $\mathrm{x}$ & \\
\hline Investments & 1255.65 & 989.90 & 797.93 & 166.30 & 2631.80 & $\mathrm{x}$ & $\mathrm{x}$ \\
\hline Manufacturing orders & 939.73 & 924.10 & 579.88 & 205.60 & 2714.60 & $\mathrm{x}$ & \\
\hline Money & 54.80 & 55.80 & 7.65 & 27.30 & 71.90 & & \\
\hline Policy rate & 5.70 & 5.41 & 3.81 & 0.07 & 17.78 & & \\
\hline Private consumption & 6404.72 & 5817.40 & 2520.83 & 2882.40 & 10859.20 & $\mathrm{x}$ & $\mathrm{x}$ \\
\hline Real effective exchange rate & 120.98 & 116.16 & 19.11 & 92.92 & 185.97 & & \\
\hline Stock index & 5357.15 & 3235.47 & 4680.25 & 607.87 & 16576.66 & & \\
\hline Unemployment rate & 6.41 & 6.00 & 1.56 & 3.90 & 10.70 & $\mathrm{x}$ & \\
\hline
\end{tabular}


Table 2: Descriptive Statistics, Japan

\begin{tabular}{|c|c|c|c|c|c|c|c|}
\hline Variable & mean & median & $\begin{array}{l}\text { standard } \\
\text { deviation }\end{array}$ & minimum & maximum & $\begin{array}{c}\text { seasonal } \\
\text { adjustment }\end{array}$ & $\begin{array}{c}\text { constant } \\
\text { prices }\end{array}$ \\
\hline Business confidence & 100.04 & 100.01 & 1.36 & 97.19 & 102.99 & $\mathrm{x}$ & \\
\hline Exports & 49842.44 & 46466.30 & 21869.22 & 19328.00 & 92048.00 & $\mathrm{x}$ & $\mathrm{x}$ \\
\hline Government bond rates, long-term & 3.62 & 2.60 & 2.60 & 0.59 & 9.29 & & \\
\hline Government spending & 74377.70 & 75541.40 & 18631.93 & 41526.60 & 102619.40 & $\mathrm{x}$ & $\mathrm{x}$ \\
\hline Gross domestic product & 436594.20 & 464400.40 & 78533.64 & 263584.00 & 536122.30 & $\mathrm{x}$ & $\mathrm{x}$ \\
\hline Hourly earnings & 19.35 & 21.77 & 8.87 & 5.32 & 36.38 & $\mathrm{x}$ & \\
\hline Hours worked & 107.00 & 104.60 & 6.38 & 97.60 & 117.90 & $\mathrm{x}$ & \\
\hline Housing index & 1257.95 & 1215.51 & 256.16 & 719.41 & 1792.39 & & \\
\hline Imports & 10719.41 & 9021.57 & 4363.59 & 4766.30 & 22238.06 & $\mathrm{x}$ & $\mathrm{x}$ \\
\hline Industrial production & 96.50 & 99.50 & 11.63 & 70.80 & 116.80 & $\mathrm{x}$ & \\
\hline Investments & 106958.24 & 111628.50 & 17593.77 & 71463.10 & 132062.90 & $\mathrm{x}$ & $\mathrm{x}$ \\
\hline Money & 546955.35 & 560591.70 & 189959.39 & 191775.30 & 863827.50 & & \\
\hline Policy rate & 2.13 & 0.75 & 2.33 & 0.10 & 9.00 & & \\
\hline Private consumption & 253331.58 & 268812.10 & 45701.13 & 159124.60 & 322336.60 & $\mathrm{x}$ & $\mathrm{x}$ \\
\hline Real effective exchange rate & 102.87 & 103.90 & 15.90 & 74.90 & 148.80 & & \\
\hline Stock index & 15352.52 & 13852.50 & 6648.18 & 6502.80 & 38915.87 & & \\
\hline Unemployment rate & 3.53 & 3.37 & 1.09 & 1.90 & 5.43 & $\mathrm{x}$ & \\
\hline
\end{tabular}

Table 3: Descriptive Statistics, United Kingdom

\begin{tabular}{|c|c|c|c|c|c|c|c|}
\hline Variable & mean & median & $\begin{array}{l}\text { standard } \\
\text { deviation }\end{array}$ & minimum & maximum & $\begin{array}{c}\text { seasonal } \\
\text { adjustment }\end{array}$ & $\begin{array}{c}\text { constant } \\
\text { prices }\end{array}$ \\
\hline Commodity price index & 64.80 & 71.75 & 28.46 & 11.30 & 108.80 & $\mathrm{x}$ & \\
\hline Exports & 63539.09 & 50948.00 & 32665.90 & 21079.00 & 125831.00 & $\mathrm{x}$ & $\mathrm{x}$ \\
\hline Government bond rates, long-term & 8.37 & 8.59 & 3.67 & 2.68 & 16.54 & & \\
\hline Government spending & 62652.69 & 58893.50 & 12910.77 & 42721.00 & 86554.00 & $\mathrm{x}$ & $\mathrm{x}$ \\
\hline Gross domestic product & 258310.17 & 235942.50 & 83004.62 & 142919.00 & 392786.00 & $\mathrm{x}$ & $\mathrm{x}$ \\
\hline Hourly earnings & 7.85 & 5.76 & 5.52 & 0.62 & 32.25 & $\mathrm{x}$ & \\
\hline Hours worked & 879.94 & 880.95 & 39.57 & 791.10 & 976.80 & $\mathrm{x}$ & \\
\hline Imports & 65471.70 & 51179.50 & 37694.21 & 20917.00 & 137342.00 & $\mathrm{x}$ & $\mathrm{x}$ \\
\hline Industrial production & 97.47 & 98.40 & 9.14 & 78.10 & 111.00 & $\mathrm{x}$ & \\
\hline Investments & 39951.38 & 36769.50 & 14695.17 & 21439.00 & 70435.00 & $\mathrm{x}$ & $\mathrm{x}$ \\
\hline Money & 719190.00 & 519200.00 & 682189.21 & 28484.00 & 2214507.00 & & \\
\hline Policy rate & 7.56 & 6.63 & 4.26 & 0.50 & 17.00 & & \\
\hline Private consumption & 158955.45 & 145788.00 & 59641.87 & 78471.00 & 251953.00 & $\mathrm{x}$ & $\mathrm{x}$ \\
\hline Real effective exchange rate & 108.89 & 108.05 & 12.36 & 83.44 & 140.27 & & \\
\hline Retail sales & 66.58 & 61.90 & 22.13 & 38.10 & 105.30 & $\mathrm{x}$ & $\mathrm{x}$ \\
\hline Stock index & 1516.62 & 1314.88 & 1118.23 & 66.90 & 3609.63 & & \\
\hline Unemployment rate & 5.39 & 4.45 & 2.68 & 1.60 & 10.60 & $\mathrm{x}$ & \\
\hline
\end{tabular}


Table 4: Descriptive Statistics, Germany

\begin{tabular}{|c|c|c|c|c|c|c|c|}
\hline Variable & mean & median & $\begin{array}{l}\text { standard } \\
\text { deviation }\end{array}$ & minimum & maximum & $\begin{array}{c}\text { seasonal } \\
\text { adjustment }\end{array}$ & $\begin{array}{c}\text { constant } \\
\text { prices }\end{array}$ \\
\hline Business confidence & 101.23 & 101.10 & 6.82 & 85.10 & 114.50 & $\mathrm{x}$ & \\
\hline Exports & 169.82 & 162.55 & 66.36 & 78.88 & 279.12 & $\mathrm{x}$ & $\mathrm{x}$ \\
\hline Government bond rates, long-term & 4.64 & 4.34 & 1.83 & 1.41 & 8.55 & & \\
\hline Government spending & 103.49 & 103.91 & 8.87 & 83.51 & 118.16 & $\mathrm{x}$ & $\mathrm{x}$ \\
\hline Gross domestic product & 545.02 & 548.87 & 49.12 & 466.33 & 630.63 & $\mathrm{x}$ & $\mathrm{x}$ \\
\hline Hourly earnings & 86.55 & 87.26 & 12.59 & 61.24 & 109.93 & $\mathrm{x}$ & \\
\hline Hours worked & 98.61 & 83.70 & 29.73 & 61.90 & 154.80 & $\mathrm{x}$ & \\
\hline Imports & 180.37 & 170.23 & 62.35 & 93.70 & 292.68 & $\mathrm{x}$ & $\mathrm{x}$ \\
\hline Industrial production & 92.78 & 90.80 & 9.28 & 78.70 & 110.20 & $\mathrm{x}$ & \\
\hline Investments & 100.32 & 98.37 & 6.33 & 89.42 & 112.51 & $\mathrm{x}$ & $\mathrm{x}$ \\
\hline Manufacturing orders & 1485.38 & 1440.20 & 451.35 & 743.60 & 2334.30 & $\mathrm{x}$ & \\
\hline Money & 85.30 & 84.20 & 16.19 & 60.00 & 117.90 & & \\
\hline Policy rate & 3.16 & 2.50 & 2.01 & 0.25 & 8.25 & & \\
\hline Private consumption & 319.36 & 325.17 & 20.53 & 273.69 & 354.20 & $\mathrm{x}$ & $\mathrm{x}$ \\
\hline Real effective exchange rate & 104.49 & 104.76 & 5.14 & 94.94 & 117.53 & & \\
\hline Stock index & 4663.03 & 4905.44 & 2114.86 & 1398.23 & 9552.16 & & \\
\hline Unemployment rate & 9.13 & 9.30 & 1.70 & 5.40 & 12.60 & $\mathrm{x}$ & \\
\hline
\end{tabular}

Table 5: Sample size and number of iterations by country

\begin{tabular}{lccc}
\hline Country & sample & first iteration & number of iterations \\
\hline USA & $1970: 1-2014: 1$ & $1980: 1$ & 128 \\
Japan & $1980: 1-2014: 1$ & $1990: 1$ & 88 \\
Germany & $1991: 1-2014: 1$ & $2001: 1$ & 44 \\
United Kingdom & $1971: 2-2014: 2$ & $1980: 2$ & 123 \\
\hline
\end{tabular}


Table 6: Comparison of level forecasts and forecasts of naïve and unbiased log-transformed models, USA

\begin{tabular}{ccccc}
\hline & level $<$ naïve & level $>$ naïve & level $<$ optimal & level $>$ optimal \\
\hline $\mathrm{h}=1$ & 5.58 & 12.81 & 5.58 & 12.80 \\
$\mathrm{~h}=2$ & 5.97 & 6.45 & 5.97 & 6.45 \\
$\mathrm{~h}=3$ & 2.91 & 2.41 & 2.91 & 2.40 \\
$\mathrm{~h}=4$ & 3.40 & 0.81 & 3.40 & 0.81 \\
$\mathrm{~h}=5$ & 3.07 & 0.38 & 3.07 & 0.38 \\
$\mathrm{~h}=6$ & 1.84 & 0.32 & 1.84 & 0.32 \\
$\mathrm{~h}=7$ & 0.86 & 0.29 & 0.86 & 0.29 \\
$\mathrm{~h}=8$ & 0.26 & 0.22 & 0.26 & 0.22 \\
\hline
\end{tabular}

Note: The table compares level forecasts, forecasts of models employing logarithms that have been retransformed taking the exponential (naïve), forecasts of models employing logarithms that have been retransformed in the theoretically optimal way (optimal). The numbers represent the percentages one model significantly outperformed the alternative according to the HNL test. "<" ("> ") indicates significantly smaller (bigger) forecast errors.

Table 7: Comparison of level forecasts and forecasts of naïve and unbiased log-transformed models, Japan

\begin{tabular}{ccccc}
\hline & level $<$ naïve & level $>$ naïve & level $<$ optimal & level $>$ optimal \\
\hline $\mathrm{h}=1$ & 2.25 & 13.65 & 2.25 & 13.65 \\
$\mathrm{~h}=2$ & 5.29 & 6.46 & 5.30 & 6.46 \\
$\mathrm{~h}=3$ & 8.80 & 2.63 & 8.82 & 2.61 \\
$\mathrm{~h}=4$ & 10.72 & 1.26 & 10.74 & 1.26 \\
$\mathrm{~h}=5$ & 8.90 & 0.55 & 8.90 & 0.55 \\
$\mathrm{~h}=6$ & 7.95 & 0.65 & 7.96 & 0.65 \\
$\mathrm{~h}=7$ & 8.29 & 0.54 & 8.31 & 0.54 \\
$\mathrm{~h}=8$ & 8.61 & 0.71 & 8.61 & 0.71 \\
\hline
\end{tabular}

Note: The table compares level forecasts, forecasts of models employing logarithms that have been retransformed taking the exponential (naïve), forecasts of models employing logarithms that have been retransformed in the theoretically optimal way (optimal). The numbers represent the percentages one model significantly outperformed the alternative according to the HNL test. "<" (">" ) indicates significantly smaller (bigger) forecast errors. 
Table 8: Comparison of level forecasts and forecasts of naïve and unbiased log-transformed models, Germany

\begin{tabular}{ccccc}
\hline & level $<$ naïve & level $>$ naïve & level $<$ optimal & level $>$ optimal \\
\hline $\mathrm{h}=1$ & 5.43 & 2.12 & 5.43 & 2.12 \\
$\mathrm{~h}=2$ & 2.54 & 1.67 & 2.54 & 1.67 \\
$\mathrm{~h}=3$ & 1.51 & 1.32 & 1.51 & 1.32 \\
$\mathrm{~h}=4$ & 1.45 & 2.34 & 1.45 & 2.34 \\
$\mathrm{~h}=5$ & 1.50 & 1.60 & 1.50 & 1.60 \\
$\mathrm{~h}=6$ & 1.45 & 1.80 & 1.45 & 1.80 \\
$\mathrm{~h}=7$ & 1.45 & 1.98 & 1.45 & 1.98 \\
$\mathrm{~h}=8$ & 1.61 & 2.27 & 1.61 & 2.27 \\
\hline
\end{tabular}

Note: The table compares level forecasts, forecasts of models employing logarithms that have been retransformed taking the exponential (naïve), forecasts of models employing logarithms that have been retransformed in the theoretically optimal way (optimal). The numbers represent the percentages one model significantly outperformed the alternative according to the HNL test. "<" ("> ") indicates significantly smaller (bigger) forecast errors.

Table 9: Comparison of level forecasts and forecasts of naïve and unbiased log-transformed models, UK

\begin{tabular}{ccccc}
\hline & level $<$ naïve & level $>$ naïve & level $<$ optimal & level $>$ optimal \\
\hline $\mathrm{h}=1$ & 20.99 & 5.78 & 20.99 & 5.78 \\
$\mathrm{~h}=2$ & 8.47 & 1.64 & 8.47 & 1.64 \\
$\mathrm{~h}=3$ & 2.34 & 1.64 & 2.34 & 1.64 \\
$\mathrm{~h}=4$ & 0.86 & 4.29 & 0.86 & 4.29 \\
$\mathrm{~h}=5$ & 0.36 & 7.58 & 0.36 & 7.58 \\
$\mathrm{~h}=6$ & 0.04 & 8.53 & 0.04 & 8.53 \\
$\mathrm{~h}=7$ & 0.01 & 6.91 & 0.01 & 6.91 \\
$\mathrm{~h}=8$ & 0.01 & 6.74 & 0.01 & 6.74 \\
\hline
\end{tabular}

Note: The table compares level forecasts, forecasts of models employing logarithms that have been retransformed taking the exponential (naïve), forecasts of models employing logarithms that have been retransformed in the theoretically optimal way (optimal). The numbers represent the percentages one model significantly outperformed the alternative according to the HNL test. "<" (">" ) indicates significantly smaller (bigger) forecast errors. 